\title{
PRIVAÇÃO DE ESCOLARIDADE: A SITUAÇÃO DO JOVEM EM CONFLITO COM A LEI
}

\author{
Riane C. F. Freitas ${ }^{1}$ \\ Gilmar Pereira da Silva ${ }^{2}$ \\ Ronaldo Marco de L. Araujo ${ }^{3}$ \\ Ana Maria Raiol da Costa ${ }^{4}$ \\ Crisolita Santos Costa ${ }^{5}$
}

\begin{abstract}
Resumo
Objetivamos analisar os dados referentes ao processo de escolarização destinado aos adolescentes e jovens que cometeram um ato infracional e ficam sob a responsabilidade do Estado no período de cumprimento de uma medida socioeducativa, isto é, como o direito à educação escolar é previsto nas legislações brasileiras e o que revelam os dados oficiais sobre isso. Por meio de pesquisa documental, analisamos os relatórios oficiais que sobre a escolarização ou não desses jovens no período de cumprimento da medida. Temos como referência teórico-metodológica o materialismo histórico-dialético. Nossos apontamentos conclusivos indicam que muito embora o Brasil possua um compêndio de normas e legislações muito avançadas para o atendimento do jovem cumpridor de medidas socioeducativas em relação às anteriores, esse modelo atual pouco avançou no se refere à escolarização em sua concretude que possibilite uma real inserção do jovem após o período de cumprimento de medida socioeducativa.
\end{abstract}

Palavras-chave: Jovem em conflito com a lei. Escolarização. Política educacional.

\section{DEPRIVATION OF SCHOOLING: THE SITUATION OF THE YOUNG PERSON IN CONFLICT WITH THE LAW}

\begin{abstract}
The objective of this study is to analyze data on the schooling process for adolescents and young people who have committed an infraction and are under the responsibility of the State in the period of compliance with a socio-educational measure, ie, the right to school education is provided for in Brazilian legislation and which reveals the official data on this. Through documentary research, we analyzed the official reports that show the schooling or non-schooling of these young people in the period of compliance of the measure. We have as a theoretical-methodological reference historical-dialectical materialism. Our concluding remarks indicate that although Brazil has a compendium of norms and laws that are very advanced for the care of the young person who complies with socio-educational measures in relation to the previous ones, this current model has not advanced much in terms of schooling in its concreteness that allows a real insertion of the young person after the period of fulfillment of socio-educational measure.
\end{abstract}


Keywords: Young person in conflict with the law. Schooling. Education politics.

\title{
PRIVACIÓN DE ESCOLARIDAD: LA SITUACIÓN DEL JOVEN EN CONFLICTO CON LA LEY
}

\begin{abstract}
Resumen
Objectivamos analizar los datos relacionados con el proceso de escolarización destinado a adolescentes y jóvenes que cometeram um ato infracción y esta sob les responsabilidad del Estado dentro del período de cumplimiento de la sanción, a saber, cómo o derecho a la educación escolar es previtos em las legislacions brasileñas e o que revelan os dados oficiales sobre isso. Por medio de investigación documental, analizamos los informes oficiales que revelan la escolarización o no de esos jóvenes en el período de cumplimiento de la sanción. Tenemos como referencia teórico-metodológica el materialismo histórico-dialéctico. Nuestros apuntes concluyentes indican que, aunque Brasil posee un compéndio de normas y legislaciones avançadas viendo en los anteriores para la atención del joven cumplidor de medidas socioeducativas, ese modelo actual de resocialización tiene poca efectividad para la reinserción del joven después del período de internación del cumplimiento de medida socioeducativa.
\end{abstract}

Palabras clave: Joven en conflicto con la ley. Escolarización. Política educativa.

\section{INTRODUZINDO O ASSUNTO}

Neste artigo, objetivamos analisar os dados educacionais dos jovens que cumprem medida socioeducativa privado de liberdade. Vale ressaltar que utilizamos alguns conceitos constantes no documento expedido pela Organização das Nações Unidas em 1985 que estabeleceu regras basilares de proteção à criança e ao adolescente para todos os países, intitulado Regras mínimas das Nações Unidas para a administração da justiça, da infância e da juventude - Regras de Beinjing, e da qual o Brasil recepcionou-as na Constituição Federal de 1988 e posteriormente, orientou e sustentou Estatuto da Criança e Adolescente - ECA (Lei 8.069/1990), tais como:

\footnotetext{
a) Jovem é toda a criança ou adolescente que, de acordo com o sistema jurídico respectivo, pode responder por uma infração de forma diferente do adulto;

b) Infração é todo comportamento (ação ou omissão) penalizado com a lei, de acordo com o respectivo sistema jurídico;

c) Jovem infrator é aquele a quem se tenha imputado o cometimento de uma infração ou que seja considerado culpado do cometimento de uma infração (VOLPI, 2014, p. 94).
}

O ECA foi resultado de grandes lutas sociais e instituído depois de um processo de redemocratização no Brasil após o fim da Ditadura Militar, em 1985. A democracia 
brasileira, com a promulgação da Constituição Federal (CF) em 1988, garantiu às crianças e adolescentes o direito de serem considerados cidadãos, recebendo a proteção integral do Estado.

A instituição do ECA em 1990 foi importante porque substituiu o Código de Menores de 1979, e foi a primeira legislação que instituiu formalmente o conceito de criança e adolescente, antes empregado pelo termo menor. Contudo, este termo "menor" era muitas vezes destinado aos menores abandonados e delinquentes, ou seja, a uma classe social.

O ECA introduziu não só uma mudança de paradigma para os cidadãos brasileiros menores de 18 anos, uma vez que a todos foi garantido direitos e deveres, independente de sua classe social, como pautou a doutrina de proteção integral e constituiu um Sistema de Garantia de Direitos (SGD) ${ }^{6}$, uma vez que essa legislação, pelo menos formalmente, tenta "romper" com o paradigma da situação irregular de marginalizados dos menores abandonados e dos menores infratores e com práticas correcionais e repressivas instaladas no atendimento aos adolescentes e jovens que passam a cumprir uma Medidas Socioeducativas, em contrapartida ao Código de Menores (LEI No 6.697/1979).

Assim, a Medida Socioeducativa no ECA passou a ter o paradigma mais educativo e menos repressivo. Isto é, agora em vez de FUNABEM - Fundação Nacional de BemEstar do Menor, encarregada de operacionalizar a nível nacional a política autoritária/repressiva de internação e das FEBEMs - Fundações Estaduais do Bem-Estar do Menor, no nível estadual, as Unidades Socioeducativas passaram a ter a responsabilidade de oportunizar aos jovens, além da sanção de uma conduta infratora para aqueles que conflitaram a lei, uma reestruturação educativa perante uma sociedade que foi violada, mediante uma determinação judicial do Juizado da Infância e Juventude no Tribunal de Justiça Estadual, com o objetivo de evitar a reincidência de atos infracionais, para aplicação aos adolescentes na faixa etária de 12 a 18 anos (e aos jovens, excepcionalmente, até os 21 anos de idade) com o objetivo de reorientar o indivíduo submetido a ela. A perspectiva era de ressocialização desse jovem por meio da garantia, entre outros, de escolarização e profissionalização.

É o artigo 112 do ECA que expressa os tipos de Medidas Socioeducativas que o juiz da Infância e Juventude pode aplicar ao adolescente que cometeu algum ato infracional, sejam elas:

I - advertência'; II - obrigação de reparar o dano ${ }^{8}$; III - prestação de serviço à comunidade $^{9}$; IV - liberdade assistida ${ }^{10} ; \mathrm{V}$ - inserção em regime de semiliberdade $^{11}$; VI - internação em estabelecimento educacional ${ }^{12}$; VII qualquer um das previstas no art. 101, I a VI. (BRASIL, 1990, s/n, grifos nosso).

São as medidas de liberdade assistida (LA), semiliberdade e internação, que mencionam a responsabilidade do Estado, por meio dos órgãos de garantia de direitos do adolescente, sobre a educação e a profissionalização, apesar da primeira (LA) prever a supervisão da frequência do acompanhamento escolar e da profissionalização do assistido, 


\section{Revista HIISTEYIDIR On-line}

é no regime de semiliberdade e internação que a atividades escolares e profissionalizantes passam a ser de co-responsabilidade das Unidades de Atendimento Socioeducativos UASES com as secretarias de educação, conforme as regras da política setorial e do princípio da incompletude institucional, portanto é responsabilidade compartilhada.

Vale frisar que sempre associada à educação, está a profissionalização, conforme se pode ver nos artigos 94, 120, 124 e 208 que tratam sobre a responsabilização pela escolarização e profissionalização de adolescentes e jovens privados de liberdade pelo Estado, entidades governamentais e não-governamentais, conforme se pode ver:

Art. 94. As entidades que desenvolvem programas de internação têm as seguintes obrigações, entre outras: (...) X - propiciar escolarização e profissionalização; Art. 120. O regime de semiliberdade pode ser determinado desde o início, ou como forma de transição para o meio aberto, possibilitada a realização de atividades externas, independentemente de autorização judicial. $\S 1^{\circ}$ São obrigatórias a escolarização e a profissionalização, devendo, sempre que possível, ser utilizados os recursos existentes na comunidade. Art. 124. São direitos do adolescente privado de liberdade, entre outros, os seguintes: (...) XI - receber escolarização e profissionalização; Art. 208. Regem-se pelas disposições desta Lei as ações de responsabilidade por ofensa aos direitos assegurados à criança e ao adolescente, referentes ao não oferecimento ou oferta irregular: VIII - de escolarização e profissionalização dos adolescentes privados de liberdade. (BRASIL, 1990, s/n).

O Art. 120 do ECA reforça essa responsabilidade dispondo que "São obrigatórias a escolarização e a profissionalização, devendo, sempre que possível, ser utilizados os recursos existentes na comunidade." (BRASIL, 1990, s/n). Isto é, ao jovem submetido à esta medida, é obrigatória a matrícula em uma escola próxima à sua residência ou da Unidade de Semiliberdade. A Lei do Sistema Nacional de Atendimento Socioeducativo - SINASE vem 22 anos depois reforçar ainda essas categorias na socioeducação:

\footnotetext{
Art. $8^{\circ}$ Os Planos de Atendimento Socioeducativo deverão, obrigatoriamente, prever ações articuladas nas áreas de educação, saúde, assistência social, cultura, capacitação para o trabalho e esporte, para os adolescentes atendidos, em conformidade com os printcípios elencados na Lei $\mathrm{n}^{\circ}$ 8.069, de 13 de julho de 1990 (Estatuto da Criança e do Adolescente).

Art. 25. A avaliação dos resultados da execução de medida socioeducativa terá por objetivo, no mínimo: I - verificar a situação do adolescente após cumprimento da medida socioeducativa, tomando por base suas perspectivas educacionais, sociais, profissionais e familiares; e II - verificar reincidência de prática de ato infracional.

Art. 53. O PIA será elaborado sob a responsabilidade da equipe técnica do respectivo programa de atendimento, com a participação efetiva do adolescente e de sua família, representada por seus pais ou responsável. III - a previsão de suas atividades de integração social e/ou capacitação profissional. (BRASIL, 2012b).
}

Deste modo, aos adolescentes cumpridores de medida socioeducativa a escolarização, assim como a profissionalização, são previstos nas legislações, inclusive a Lei de Diretrizes e Bases da Educação Nacional - LDB, em seu artigo $1^{\circ} \S 2^{\circ}$, é enfática ao afirmar que "A educação escolar deverá vincular-se ao mundo do trabalho e à prática social", 
este mesmo dispositivo legal determina em seu artigo $5^{\circ} \S 2^{\circ}$, que em “[...] todas as esferas administrativas, o Poder Público assegurará em primeiro lugar o acesso ao ensino obrigatório, [...] contemplando em seguida os demais níveis e modalidades de ensino, conforme as prioridades constitucionais e legais." (BRASIL, 1996).

Compreendemos escolarização como período da educação escolar que se desenvolve, predominantemente, por meio do ensino, não em uma perspectiva meramente pedagógica, mas também histórico-política, em instituições próprias e deverá vincular-se ao mundo do trabalho e à prática social, conforme determina o compêndio de legislações já citadas, inclusive na Lei de Diretrizes e Bases da Educação - LDB (LEI 8394/1996) que possibilite a construção de uma perspectiva transformadora.

Já por profissionalização compreendemos a ação de profissionalizar, de atribuir o caráter de uma profissão a uma atividade, isto é, com critérios de formação, carreira, condições de estabilidade e de progresso na atividade. (FREITAS, 2017), levando-se em consideração que a "mediação profissional dificilmente se separa da mediação política". (GRAMSCI, 1992, p. 13).

Chamamos a atenção para o termo utilizado pelo ECA para a instituição responsável pelo acolhimento de internação e de semiliberdade é de "estabelecimento educacional", tentando a legislação tornar esse tempo de recolhimento um período de promoção do processo educativo e de responsabilização para a vida em sociedade de modo a evitar a reinfração destes jovens em conflito com a lei.

Destarte, na perspectiva sociopedagógica da medida socioeducativa, o Estado deve oportunizar aos jovens submetidos a ela uma reestruturação de uma nova prática social e educacional, constituindo um aparato governamental tendo todos os poderes e esferas públicas (União, Estados, Municípios, Executivo, Legislativo e Judiciário), além da sociedade civil, comprometidos com o Sistema de Garantia de Direitos (SGD), uma vez que a Educação como dever do Estado está prevista tanto na Constituição Federal quanto em outras leis como no ECA e outros tratados internacionais do qual o Brasil é signatário.

Em 2012, no contexto de delineação das políticas de atendimento à infância e juventude, foi instituído o Sistema Nacional de Atendimento Socioeducativo - SINASE, Lei $n^{\circ} 12.594 / 2012$. O SINASE é constituído de um

[...] conjunto ordenado de princípios, regras e critérios que envolvem a execução de medidas socioeducativas, incluindo-se nele, por adesão, os sistemas estaduais, distrital e municipais, bem como todos os planos, político e programas específicos de atendimento a adolescente em conflito com a lei. (BRASIL, 2012b).

Com isso, a Lei do SINASE é de responsabilidade da Secretaria de Direitos Humanos da Presidência da República (SDH/PR), a qual tem a missão de desenvolver políticas públicas voltadas à promoção dos direitos da criança e do adolescente, regulamenta todo o atendimento socioeducativo para crianças e adolescentes com mais de 12 anos e menos de 


\section{Revista HIISTEYIDIR On-line}

18 anos de idade que tenham cometido algum ato infracional, além de dar as disposições gerais sobre a instalação, manutenção das unidades e programas de atendimento, ressaltando a competência da União, Estados e Municípios.

No que se refere ao financiamento, o SINASE deverá ser co-financiado além dos entes federados que instituíram o sistema socioeducativo, pelos Fundos: Da Criança e do Adolescente (nas três esferas); Fundo de Prevenção, Recuperação e de Combate às Drogas de abuso (Funcab); Fundo de Amparo ao Trabalhador (FAT) e Fundo Nacional do Desenvolvimento da Educação (FNDE). Este último desde que, o ente federado que solicitou o recurso tenha assinado o Plano de Metas Compromisso Todos Pela Educação e elaborado o respectivo Plano de Ações Articuladas (PAR).

Estes dispositivos legais representam um avanço para a sociedade democrática, pois obriga o Estado a se responsabilizar pelas políticas para a criança e o adolescente que infringiu a lei, além de determinar de onde vêm os recursos.

É importante observamos que com a instituição do SINASE, podemos perceber as relações entre trabalho e educação andando lado a lado, tanto com a destinação de recursos do FAT quanto do FNDE, uma vez que, como já vimos anteriormente, a educação escolar para o jovem privado de liberdade está sempre ligada a questão da educação profissional.

Questionamos que escolarização e profissionalização são essas? Certamente, pelo fato delas estarem inseridas na sociedade capitalista, acaba reproduzindo a dualidade de classes na educação, que por sua vez configura uma educação profissional que requer conhecimentos básicos limitados à execução de tarefas de forma aligeirada, que historicamente é destinada aos trabalhadores, em contraposição à escola propedêutica de formação geral que forma o intelectual e o líder dirigente.

Sobre essa dualidade que se reproduz na educação profissional, Araujo e Rodrigues (2010) revelam que o projeto de educação para o capital visa "[...] à segregação do desenvolvimento das capacidades de pensar e de fazer do trabalhador e à acomodação social ante a realidade dada", com o objetivo de adestramento e não de contestação. De acordo com esses os autores, essas formações não são capazes e não dão conta de "[...] promover qualificações amplas e duradouras entre os trabalhadores, pelo contrário, o ideário consiste em continuar perpetuando a divisão social e técnica do trabalho." (ARAUJO e RODRIGUES, 2010, p. 52). São formações aligeiradas, que dão apenas um requisito mínimo para se manter no trabalho precarizado.

Nessa lógica, Moura (2007, p. 5) reforça que a educação profissional trata-se de uma “[...] vertente educacional, geralmente de caráter mais instrumental é permitida aos filhos das classes populares, enquanto a educação básica de caráter mais propedêutico é dirigida à formação das elites." Os dados que veremos a seguir confirmam esta tese. 
Nesse mesmo sentido converge Saviani (2014, p. 86) quando afirma que a tão “[...] desejada universalização da educação não passa de um discurso paradoxal que se manifesta nas expectativas contraditórias depositadas na escola, uma vez que a educação para a classe trabalhadora não será igual e equânime à educação das classes dirigentes", visto que o Estado quando aplica as Medidas Socioeducativas junto ao jovem que cometeu infração, o direciona para uma formação que tem sua “[...] marca social [...]”. (GRAMSCI, 1982, p. 136).

Nesse caso, a marca da escola para os pobres é a profissional, que Gramsci (1982) chama de interessada, isto é, com finalidades práticas imediatas. Para este autor, o principal aspecto paradoxal é que este tipo de escola ganha "ares" de democrático ao se fazer inclusiva para aqueles que estão à margem da sociedade, quando "[...] na realidade, não só é destinada a perpetuar as diferenças sociais como ainda cristalizá-las em formas chinesas." (GRAMISCI, 1982, p. 136).

Diante do clamor social por uma "[...] sociedade mais justa, este mesmo sistema, se utiliza de mecanismos que introduz a comunidade/escola como uma variável significativa do "fazer justiça" (FREITAS, 2017, p. 24) aludindo a um tipo de sociabilidade e adaptabilidade do capital que pode caracterizar-se em um mecanismo de reconfiguração e de desresponsabilização do Estado pelas políticas para a juventude, pois transfere para a escola a responsabilidade "de fazer justiça" sem uma real transformação social.

O que se pode destacar é que o capital tem um modo peculiar de fazer justiça, onde as próprias normas são produzidas de modo a apresentar espaço para que tudo fique de acordo com o desenho antes estruturado. Deste modo os discursos por mais progressistas que se apresentem deixam espaço para que se reproduza a lógica do Capital, isto quer dizer que, as rupturas são necessárias e elas só ocorrem no embate com a hegemonia dominante construída ideologicamente como algo perene e como a única forma de organização social possível.

\section{DE QUE CONTEXTO PARTIMOS?}

Dados do relatório realizado pela Comissão de Infância e Juventude do Conselho Nacional do Ministério Público, denominado "Um Olhar Mais Atento às Unidades de Internação e de Semiliberdade para Adolescentes", efetivado por meio de inspeções nas unidades de internação e de semiliberdade em 2013 registram a presença de 20.081 adolescentes em cumprimento de medidas de privação de liberdade. Destes, 18.378 cumprem medida socioeducativa de internação (provisória, definitiva e internação-sanção), enquanto 1.703 estão no regime da semiliberdade.

Os dados revelaram que $95 \%$ desses jovens são do sexo masculino, a maioria deles (cerca de 70\%) têm entre 16 e 18 anos. O segundo grupo mais numeroso é de meninos entre os 12 aos 15 anos de idade. O relatório compara o perfil dos jovens com os dados de evasão 
escolar da Síntese de Indicadores Sociais, divulgada em 2010 pelo IBGE, para mostrar a relação entre os dois indicadores - ou seja, a faixa etária com maior índice de evasão escolar é também a que apresenta maior número de internos nos sistemas de internação e de semiliberdade (16 a 18 anos). De acordo com Frigotto (2004, p. 182), há

[...] um número significativo de jovens das grandes capitais violentados em seu meio e em suas condições de vida, que se enquadram numa situação que, no mundo da física, se denomina de ponto de não-reversibilidade. Trata-se de grupos de jovens que foram tão desumanizados e socialmente violentados que se tornam presas fáceis do mercado da prostituição infanto-juvenil ou de gangues que nada têm a perder ou constituem um exército de soldados do tráfico.

A relação entre juventude, criminalidade, judicialização da vida, educação e trabalho são sobredetermindas pela relação entre o direito, que controla a vida em sociedade e o modo de produção no qual estão inseridos esses jovens. Nesse sentido, a articulação entre neoliberalismo e reestruturação produtiva, no contexto da reorganização contemporânea do capital, aumentam dramaticamente os níveis de desemprego e de subemprego no mundo, levando um enorme contingente de trabalhadores à condição de massa popular destituída das bases sociais indispensáveis para sua reprodução. É essa massa popular que será especialmente afetada pelas políticas de encolhimento do aparato social do Estado, por um lado, e pelo recrudescimento da exploração da força de trabalho, de outro. Dando origem ao que alguns autores denominam de "[...] classes perigosas." (JINKINGS, 2007, p. 3). E de acordo com Lemos (et. al., 2014, p. 162)

[...] estar em "perigo" é uma forma de afirmar a necessidade de proteção na construção de um futuro, abrindo a possibilidade de uma vida segura. Já "ser perigoso" é uma indicação de controle, não das condições de vida, mas da pessoa, do seu corpo. Quem está em perigo, tem que ser acudido; quem é perigoso, tem que ser controlado e/ou eliminado.

Ou seja, a mesma classe que está em "perigo" é a mesma que é controlada pelo aparato opressor do Estado: a classe trabalhadora. Há teóricos como Wacquant (2002) que analisam a estrutura repressora do Estado, dirigida prioritariamente às comunidades consideradas mais "propensas" ao crime, ou seja, as populações que têm uma inserção precarizada no mercado de trabalho e se encontram fora cada vez mais, reduzindo a rede de proteção estatal. Já Giorgi (2006), que analisa o período fordista e o pós-fordista, afirma que a partir de 1970 passamos a ter o período da "[...] economia política da pena" onde são pobres, desempregados, mendigos e migrantes as novas "[...] classes perigosas" que devem ser individualizadas e separadas da força de trabalho. Portanto, o objetivo do sistema de controle passou a ser o de '[...] neutralizar a 'periculosidade' das 'classes perigosas' através de técnicas de prevenção do risco, que se articulam principalmente sob as formas de vigilância, segregação urbana e contenção carcerária”. (GIORGI, 2006, p. 28). 
Esses estudos mostram como segmentos sociais precarizados, destituídos de capital, principalmente durante a vigência do Estado fordistakeynesiano, deu lugar não só ao fortalecimento do aparelho prisional estatal, mas também à forte vigilância sobre as denominadas "classes perigosas", por meio da utilização do aparato de proteção social do governo que, desse modo, se torna menos focalizado na proteção da pobreza e mais voltado ao seu controle.

A desproporcional dilatação destas "classes perigosas" é formada, portanto, de um exército de excluídos do capital. Com efeito, é justamente buscando a repressão da "[...] gigantesca massa de miseráveis criada pela reestruturação contemporânea do capital, que o Estado fortalece ainda mais seu aparelho de coerção, com o objetivo final de manutenção da ordem social" (JINKINGS, 2007, p. 129) e os jovens estão cada vez mais aumentando os índices nos cárceres.

Nesse mesmo sentido, Melossi e Pavarini - em sua clássica obra Cárcere e Fábrica: As origens do sistema penitenciário (séculos XVI - XIX) - definem a relação capital/trabalho assalariado como chave para compreender a instituição carcerária, na qual afirmam que no violento processo de acumulação primitiva do capital nos séculos XV e XVI, “[...] os camponeses se concentram nas cidades, onde a insuficiente absorção da mão de obra pela manufatura e a inadaptação à disciplina do trabalho assalariado originam a formação de massas de desocupados urbanos." (MELOSSI e PAVARINI, 2014, p. 5).

De acordo com os estudos de Melossi e Pavarini (2014, p. 96), os “[...] mendigos, vagabundos, ladrões e outros delinquentes dos centros urbanos" eram denominados de classes perigosas, não como resultado de determinações estruturais, “[...] mas interpretados como expressão individual de atitudes defeituosas, tangidos para as workhouses", que tinha como objetivo resolver problemas de exclusão social da gênese do capitalismo. (MELOSSI e PAVARINI, 2014, p. 96).

Assim, desde sua origem o encarceramento foi para os pobres, fato que nos dias atuais não é diferente, pois de acordo com o Relatório do Infopen ${ }^{13}$ (2014) os problemas no "[...] sistema penitenciário que se concretizam em nosso país, devem nos conduzir a profundas reflexões, sobretudo em uma conjuntura em que o perfil das pessoas presas é majoritariamente de jovens negros, de baixa escolaridade e de baixa renda" (BRASIL, 2014, p. 6), apesar do último relatório publicado em 2017 não se apresentar um quadro situacional da renda dos mais de 726.712 presos internos em estabelecimentos penais, o que certamente não é uma omissão voluntária, pois os dados exatos da renda dos presos deixaria mais evidente o fosso social da sociedade brasileira. (BRASIL, 2017, p. 7).

Este é o quadro no qual se constitui a relação entre aparelho coercitivo estatal e pobreza, sob a vigência do neoliberalismo, que tem reflexo nos altos índices de violência, pois dados do Mapa da Violência de 2014/Jovens do Brasil (WAISELFISZ, 2014), por meio de estudos históricos realizados em São Paulo e Rio de Janeiro mostram que as epidemias e 
doenças infecciosas, eram as principais causas de morte entre os jovens cinco ou seis décadas atrás. Já na década atual, estas causas foram progressivamente substituídas pelas denominadas causas externas, principalmente acidentes de trânsito e homicídios. Em 1980, 50\% das mortes dos jovens eram de causas externa. Em 2012 essa taxa passou para 71,1\%, sendo o Brasil, de acordo com a Organização Mundial da Saúde (OMS) o $8^{\circ}$ país com maior taxa de homicídios (por 100 mil habitantes) na População Jovem.

No Atlas da Violência de 2017 os números de homicídios de jovens são mais assustadores. Somente o Estado do Pará, teve um aumento de $78 \%$ do número de jovens assassinados. Saltou de $1082 \mathrm{em} 2005$, para $1936 \mathrm{em}$ 2015. De acordo com este documento, mais de 318 mil jovens foram assassinados no Brasil entre 2005 e 2015. (CERQUEIRA et. al., 2017).

Este avanço brusco no índice de violência dos jovens nos induz a afirmar o abandono que esta população sofre quando o Estado nega-lhes acesso à educação, saúde, cultura, trabalho, lazer entre outras políticas públicas. Por outro lado, numa lógica inversa, este jovem que teve todos esses direitos negados, após o cometimento de uma infração, sob pena de punição, o Estado é obrigado a lhe ofertar, conforme a Lei do SINASE.

\section{O SISTEMA LEGAL A SERVIÇO DO CAPITAL: PRODUÇÃO DE MÃO-DE-OBRA NO PUNITIVO}

Consideramos que o cárcere é o reflexo da organização social e econômico vigente e todo esse aparato repressor está engendrado por uma lógica de justiça que tem ligação direta com a lógica econômica, que reflete nas relações sociais seja no trabalho, na educação, na cultura, na religião, etc., que pode ocorrer por meio de contrato tácito ou explícito, uma vez que, com o fortalecimento da sociedade moderna capitalista, a igreja e o direito divino perdem seu poderio para a burguesia e direito positivado por meio, do contrato social, passa a reger a vida em sociedade. (FREITAS, 2017).

Marx (2008, p. 47) considera que "[...] o modo de produção da vida material condiciona o processo de vida social, política e intelectual." Nesse sentido, o Direito e a Justiça são resultados dessas condições materiais de existência. É o que afirma quando diz que: "Não é a consciência dos homens que determina o seu ser; ao contrário; é o seu ser social que determina a sua consciência.” (MARX, 2008, p. 47). Marx considera que não são as leis, a religião, a cultura que criam o homem, mas o contrário.

Em 1845, na sua análise sobre a situação da classe trabalhadora na Inglaterra, Engels (2010, p. 248) escreveu que a “[...] delinquência acompanhou a expansão da indústria e, que a cada ano, há uma relação direta entre o número de prisões e o de fardos de algodão consumidos", afirmando que a revolta dos operários contra a burguesia seguiu de perto o 
desenvolvimento da indústria e atravessou diversas fases, sendo o crime a forma mais estéril e brutal da revolta.

O próprio Engels afirmou que a hostilidade ao proletariado está na base do ordenamento jurídico, pois, "as leis são necessárias porque existem os despossuídos" e sempre está a favor dos interesses do burguês. Sobre isso Engels considerou:

Claro que para o burguês, a lei é sagrada: trata-se de obra sua, votada com sua concordância, produzida para protegê-lo e garantir seus privilégios; ele sabe que, embora uma lei singular possa prejudicá-lo eventualmente, o conjunto de legislação assegura seus interesses e sabe, sobretudo, que o caráter sagrado da lei, a intangibilidade da ordem social consagrada pela participação ativa da vontade de uma parte da sociedade e pela passividade da outra, é o sustentáculo mais poderoso de sua posição social. O burguês encontra-se a si mesmo na lei, como se encontra em seu próprio deus - por isso ele a considera sagrada (ENGELS, 2010, p. 312).

Nesse sentido, vemos na passagem da sociedade feudal para a época moderna a adequação do sistema punitivo ao novo modo de produção, pois “[...] a estrutura econômica da sociedade capitalista nasceu da estrutura econômica da sociedade feudal. A decomposição desta liberou elementos para a formação daquela." (MARX, 2008, p. 828). Assim, de acordo com Georg Rusche e Otto Kirchheimer (2004), para cada modo de produção corresponde uma forma de punição. No caso da nascente sociedade capitalista, não era mais viável o disciplinamento pelas penas corporais, devido a necessidade de formar operários disciplinados.

Com a emergência do sistema fabril e a consequente valorização do corpo humano como instrumento fundamental da produção, surge uma nova forma de punição, ideal para o sistema, que não só preserva o corpo, como também o educa para a submissão para o trabalho: a prisão [...] Pode-se considerar que, do século XVI até o fim do século XVIII, houve uma transição entre o período anterior, marcado pela predominância das penas corporais, e o período posterior, quando a pena de reclusão se estabeleceu definitivamente a partir do início do século XIX. (JINKINGS, 2013, p. 76).

Deste modo, a sociedade capitalista, que intensificou a divisão entre as classes e aprofundou as mazelas de uma sociedade escravista para uma sociedade de homens "livres", de proprietários de terra e não-proprietários, trouxe consigo também a manutenção pelo Estado do controle da força de trabalho devido à escassez de mão de obra. Assim, os mendigos, pobres e desvalidos, prostitutas que aglomeravam as cidades - pois tinham sido expulsos de suas terras -, foram encarcerados como "vagabundos saudáveis" para servir como exército de reserva para a crescente indústria.

O roubo dos bens da Igreja, a alienação fraudulenta dos domínios do estado, a ladroeira das terras comuns e a transformação da propriedade feudal e do clã em propriedade privada moderna, levada a cabo com terrorismo implacável, figuram entre os métodos idílicos da acumulação primitiva. Conquistaram o campo para a agricultura capitalista, incorporaram as terras ao capital e proporcionaram à 
indústria das cidades a oferta necessária de proletários sem direitos. (MARX, 2008, p. 847).

Destarte, a disciplinarização do corpo, necessária para acomodar e "enquadrar" a nascente classe proletária, resistente a um novo modelo de vida, necessitava de uma legislação que Marx denominou de "[...] sanguinária contra a vadiagem." (MARX, 2008, p. 848). De acordo com o autor, "[...] o lavrador se torna proletário ou indigente não por ter sido eliminada a servidão, mas por ter sido suprimida a propriedade que tinha do solo que cultivava." (MARX, 2008, p. 836).

É fácil imaginar o grande choque e conflito produzidos pelos moradores do campo que passaram a residir nas cidades no século XVI, visto que no Brasil, no século XX, vimos às cidades abarrotadas de pessoas vindas do campo estimuladas pelo êxodo rural, com a promessa de uma vida melhor, com trabalho remunerado que não foi absolvida pela crescente industrialização principalmente em meados da década de 1970 e ocasionou grandes desigualdades sociais, especialmente por não ter conseguido absorver a mão-deobra por falta de qualificação, imagine-se esta situação há aproximadamente 500 anos. Segundo Engels (2010, p. 46), “[...] velhos moradores das proximidades das cidades, nunca haviam ido a elas, até o momento em que as máquinas os despojaram de seu ganha-pão, obrigando-os a procurar trabalho na cidade."

Foi com o reconhecimento oficial do pauperismo pela rainha Elizabeth que a Inglaterra, berço da industrialização e, como diz Engels (2010, p. 45), “[...] o terreno clássico dessa revolução", instituiu a lei do pobre, introduzindo um imposto de assistência a estes que foi rejeitado por alguns proprietários de terras e arrendatários que, de acordo com Marx (2008, p. 835), tentaram "[...] um método engenhoso com o qual se pode afastar todas as confusões que ocorrem na aplicação da lei”, sugerindo que a igreja construísse uma cadeia na paróquia onde seria "[...] negada qualquer ajuda ao pobre que nela não se deixar encarcerar", fazendo do encarceramento um local onde os proprietários de terra pudessem "[...] alugar os pobres" e as paróquias sairiam lucrando com esse aluguel. O objeto de "projeto de "lei" era propor o "[...] encarceramento e o trabalho compulsório dos pobres, de modo que ficará sem direito a qualquer auxílio aquele que se opuser ao encarceramento. Com isso, esperamos que pessoas se abstenham de requerer socorro." (BLAKEY apud MARX, 2008, p. 835).

A criação de uma legislação específica para combater os delitos contra a propriedade era uma das principais preocupações da burguesia urbana emergente. Deste modo, conforme Rusche e Kirchheimer (2004, p. 32), o tratamento do direito criminal era mais severo para um "[...] errante ou alguém de baixo status social".

O resultado desta lei, como comentado anteriormente, foi o fortalecimento do sistema penal, principalmente com o encarceramento dos pobres nas "casas de correção". De acordo 
com Rusche e Kirchheimer (2004, p. 31) a intensificação dos conflitos sociais que marcou a transição para o capitalismo entre os séculos XIV e XV,

[...] levou à criação de leis mais duras, dirigidas contra as classes subalternas. $\mathrm{O}$ crescimento constante do crime entre os setores do proletariado empobrecido, sobretudo nas grandes cidades, tornou necessário às classes dirigentes buscar novos métodos que fariam a administração da lei penal mais efetiva.

Segundo os autores, a casa de correção "[...] foi um ponto alto do mercantilismo e possibilitou o incremento de um novo modo de produção. A importância econômica da casa de correção desapareceu, entretanto, com o surgimento do sistema fabril." (RUSCHE e KIRCHHEIMER, 2004, p. 31). Contudo, Jinkings (2013, p. 77) esclarece que os objetivos da casa de correção era "[...] incutir a disciplina fabril em segmentos da população avessos ao trabalho", ou seja, disciplinar os corpos de ex-homens livres a um novo modo de produção.

De acordo com Marx (2008, p. 848),

[...] os ancestrais da classe trabalhadora atual foram punidos inicialmente por se transformarem em vagabundos e indigentes, transformação que lhes era imposta. A legislação os tratava como pessoas que escolhem propositalmente o caminho do crime, como se dependesse da vontade deles prosseguirem trabalhando nas velhas condições que não mais existiam.

Como as novas condições impostas era o trabalho no sistema fabril, as prisões serviram como importante veículo disciplinador, já que a escola estava voltada para aqueles que não viviam do trabalho, visto que, de acordo com Saviani (2007, p. 157)

\footnotetext{
O desenvolvimento da sociedade de classes, especificamente nas suas formas escravista e feudal, consumou a separação entre educação e trabalho. No entanto, não se pode perder de vista que isso só foi possível a partir da própria determinação do processo de trabalho. Com efeito, é o modo como se organiza o processo de produção - portanto, a maneira como os homens produzem os seus meios de vida - que permitiu a organização da escola como um espaço separado da produção. Logo, a separação também é uma forma de relação, ou seja nas sociedades de classes a relação entre trabalho e educação tende a manifestar-se na forma da separação entre escola e produção.
}

Nesse caso, como a escola não podia instruir a grande massa de pobres e desvalidos, mesmo que ela assuma, na sociedade capitalista o caráter de pública, universal, laica e obrigatória, o cárcere passa a ser o principal instrumento de "domesticação" com fins de reeducação da classe proletária, intensificando a divisão entre trabalho manual e trabalho intelectual. De acordo com Marx (2008), esse sistema de expansão do capital e a "coação surda das relações econômicas consolida o domínio do sistema capitalista sobre o trabalhador", dando origem à chamada acumulação primitiva, onde o Estado emprega a força para "regular" o salário dentro dos limites convenientes à produção da mais-valia. 
O Estado que deixa de ser absolutista para se tornar burguês, necessita ser forte e ter uma legislação que reprima veementemente qualquer força contrária à economia de mercado. Daí nasce o [...] "indivíduo em contraposição à sociedade" (SAVIANI, 2014, p. 17) e o jusnaturalismo como forma de regular a vida em sociedade. Assim nasce e se fortalece o modo de produção denominado Capitalista.

O fortalecimento da economia de mercado traz consigo novas relações entre o dono dos meios de produção e os proletários, que vendem sua força de trabalho em troca de um salário. A propriedade da terra e a propriedade do trabalho precisam ser reguladas pelo Estado para evitar conflitos. Assim nasce a sociedade política que, de acordo com Locke (2009), só existe onde "[...] homens concordam em desistir de seus poderes naturais e erigir uma autoridade comum para decidir disputas e punir ofensores" (LOCKE, 2009, p. 7) para isso, a estrutura social deve deixar de fundar-se em laços naturais para pautar-se em laços propriamente sociais, isto é, produzidos pelos próprios homens. Trata-se da sociedade contratual, cuja base é o direito positivo e não mais o direito natural ou consuetudinário. (SAVIANI, 2007, p. 158).

É notório que o contexto socioeconômico atual tem como correspondente um novo regime de segregação, de controle em massa, tanto de jovens quanto adultos, principalmente os pertencentes às classes desprovidas de capital que são consideradas pelo Estado como mais "propensas" ao crime e ao o encarceramento, constituindo-se em um processo de criminalização da pobreza. Busca-se com isso não só a "correção" e a punição pelo crime cometido, mas também a disciplinarização, submissão e docilização do infrator da lei junto ao aparato coercitivo estatal, tendo o sistema prisional papel fundamental na repressão e no controle da população miserável.

Os dados oficiais atuais trazem resultados alarmantes no que se refere ao encarceramento de pessoas. "As prisões evidenciam-se como instrumento privilegiado de repressão no aparato coercitivo estatal desde as origens do capitalismo, no neoliberalismo atinge-se o ápice no emprego do aprisionamento de massa como política pública de gestão da pobreza" (JINKINGS, 2007, p. 3), em uma lógica desumanizadora do capital, sendo o Brasil o $3^{\circ}$ país com a maior população prisional no mundo (726.712 mil pessoas em junho de $2016^{14}$ ), ocupando o $1^{\circ}$ lugar entre os países da América do Sul, de acordo com Levantamento Nacional de Informações Penitenciárias (Infopen) $)^{15}$ - com dados consolidados referentes a todo o ano de 2015 e o primeiro semestre de 2016.

Nesse sentido, a população prisional brasileira aumentou em números absolutos em $707 \%$ entre os anos de 1990 a $2016^{16}$, sendo que no ano de 2004 , mais de 3 milhões de brasileiros saíram da miséria e em 2005, 7 milhões de brasileiros subiram para a classe média, segundo a Fundação Getúlio Vargas. Confirmando a tese de Engels levantada em 1845 , isto é, crescimento econômico não significa desenvolvimento social. É a “[...] incorrigibilidade da lógica perversa do capital”, como refere Mészáros (2008, p. 34), 


\section{Revista HIISTEYIDIR On-line}

características de um sistema capitalista tardio, que exauriu a sua capacidade civilizatória e agora, para manter-se, destrói os direitos sociais historicamente conquistados e o meio ambiente.

Essas políticas de encarceramento da população atingem principalmente a população masculina ( $84 \%$ ), pouco escolarizadas ( $41 \%$ não completaram o ensino fundamental) ${ }^{17}$ e em sua maioria composta por jovens de 18 a 29 anos (55\%). Apesar do crescimento da população carcerária nas faixas etárias mais velhas, a população presa continua sendo a jovem. No que se refere aos dados de cor e raça, os bancos de dados sempre são muito precários, contudo, de acordo com as informações do InfoPen, no ano de 2016 cerca de $64 \%$ da população carcerária era de negros (pretos e pardos). Na contramão, no que se refere à cor dos homicídios no Brasil, o Mapa da Violência no Brasil/Homicídios e Juventude no Brasil, mostra

[...] uma acentuada tendência de queda no número de homicídios da população branca e de aumento no número de vítimas na população negra. Essa tendência se observa tanto para o conjunto da população quanto para a população jovem" [...] Assim, o índice de vitimização de jovens negros, que em 2002 era de 79,9, sobe para 168,6: para cada jovem branco que morre assassinado, morrem 2,7 jovens negros. Mas persiste entre os jovens o fato de que os significativos incrementos nos índices de vitimização negra podem ser atribuídos mais às quedas nos homicídios brancos do que a incrementos nos assassinatos de negros (WAISELFISZ, 2013, p. 87).

Vale ressaltar, que historicamente no Brasil, há um trabalho ideológico no sentido do embranquecimento da população, uma vez que a população autodeclarada branca é de 78,5\% na região Sul, sendo 3,6\% a população preta; já a região nordeste é a que mais se autodeclara preta, com $8,1 \%$, predominando nesta a população parda, com $62,7 \%$ no Norte e $71,2 \%$ no Nordeste, de acordo com o censo do IBGE de 2010.

Essa realidade reflete que a exclusão por cor também se reflete na escola, pois, de acordo com pesquisas do IPEA (2005), enquanto metade dos brancos finaliza o ensino médio, apenas $33 \%$ dos negros consegue realizá-lo. Podemos depreender, concordando com Frigotto $(2004$, p. 88$)$, que o

Preconceito com os negros e os jovens negros, do ponto de vista da criminalidade, está mais do que caracterizado na sociedade brasileira. Embora esteja havendo uma maior conscientização, fruto da organização crescente do movimento negro, as instituições jurídicas e a própria imprensa exigem apuração dos fatos quando eles acontecem com negros famosos.

Assim, os dados mostram no Brasil o jovem que mais está morrendo compõe a minoria da população e tem a cor preta. Assim como os negros (pretos e pardos) são os que mais morrem, são eles também que formam a maior população carcerária.

Essas classificações não são inocentes, assim como a omissão de dados sobre a renda tanto no Mapa da Violência quanto no Panorama Nacional de Execução das Medidas 
Socioeducativas de Internação, do CNJ e nos relatórios do Ministério Público. Contudo, em uma pesquisa realizada em 2003 pelo IPEA (Instituto de Pesquisa Econômica Aplicada) e Ministério da Justiça, $66 \%$ desses jovens viviam em famílias extremamente pobres.

Nesse sentido, os dados revelam que o encarceramento brasileiro incide sobre homens, negros, jovens e pobres, que em sua maioria não completaram o ensino fundamental e o médio, evidenciando uma política de encarceramento de classes, numa lógica desumanizadora.

Destacamos que nossa pesquisa é com os jovens cumpridores de medidas socioeducativas. Optamos por analisar os jovens, especialmente porque, de acordo com o Relatório do Panorama Nacional - A execução das Medidas Socioeducativas de Internação Programa Justiça Jovem (BRASIL, 2012a), do Conselho Nacional de Justiça, o jovem em privação da liberdade que está cumprindo a medida socioeducativa no Brasil, tem em média 16,7 anos, sendo esta a maior faixa etária do cometimento do primeiro ato infracional, período que, de acordo com a Lei de Diretrizes e Bases da Educação Nacional (Lei 9394/2006), o jovem deveria está terminando o ensino médio, etapa final da educação básica, que tem como finalidades:

\begin{abstract}
I - a consolidação e o aprofundamento dos conhecimentos adquiridos no ensino fundamental, possibilitando o prosseguimento de estudos; II - a preparação básica para o trabalho e a cidadania do educando, para continuar aprendendo, de modo a ser capaz de se adaptar com flexibilidade a novas condições de ocupação ou aperfeiçoamento posteriores; III - o aprimoramento do educando como pessoa humana, incluindo a formação ética e o desenvolvimento da autonomia intelectual e do pensamento crítico; IV - a compreensão dos fundamentos científicotecnológicos dos processos produtivos, relacionando a teoria com a prática, no ensino de cada disciplina. (BRASIL, 1996).
\end{abstract}

Contudo, dados do mesmo relatório informam que $57 \%$ dos jovens não frequentavam a escola antes de ingressar na unidade, $86 \%$ dos adolescentes informaram que cursavam o ensino fundamental, sendo o percentual dos adolescentes cumpridores de medida socioeducativa não alfabetizados atingiu o índice de $8 \%$. No entanto, este índice nacional comporta uma disparidade entre as regiões, considerando que no Nordeste $20 \%$ dos adolescentes entrevistados declararam-se analfabetos e no norte, $14 \%$, enquanto no Sul e no Centro-Oeste, $1 \%$. As regiões Norte e Nordeste também possuem o menor índice de internos que concluíram o Ensino Médio, sendo o índice de 4\% e 6\%, respectivamente. No contexto nacional, entre todos os adolescentes analfabetos, $44 \%$ destes encontra-se na Região Nordeste. Sendo que a região Norte e Nordeste está abaixo da média nacional de adolescentes que pararam os estudos aos 14 anos, conforme dados do Relatório do Panorama Nacional - A execução das Medidas Socioeducativas de Internação Programa Justiça Jovem (BRASIL, 2012a).

Essa realidade do sistema educacional brasileiro não é somente para os jovens que conflitaram a lei, mas também dos jovens pobres que não deixam de ser "priosioneiros" de 
um sistema segregador, que sonega os direitos básicos, como a escolarização. De acordo com Carrano, Marinho e Oliveira (2015, p. 1441),

[...] é fácil notar os efeitos deletérios da irregularidade das trajetórias escolares no ensino médio. Esse sistema é marcado por processos de escolarização que atravessa tanto o ensino fundamental quanto o médio. Esse sistema é marcado por processos de escolarização de baixa infraestrutura e insuficiente formação acadêmica que a escola consegue oferecer e na socialização que possibilita.

O próprio ECA determina que no período de cumprimento das medidas socioeducativas tanto no regime de semiliberdade quanto no de internação, deve ser garantido a escolarização e a profissionalização. Contudo, verifica-se que estes dispositivos legais não estão sendo respeitados. O mesmo relatório do $\mathrm{CNJ}$ mostra que em regiões brasileiras com expressiva quantidade de adolescentes internos maiores de 18 anos há um histórico de evasão escolar em torno de $42 \%$. Deste modo, a adoção de medidas mais adequadas de escolarização nos estabelecimentos com uma proposta pedagógica consolidada que possibilite ao jovem ter condições favoráveis que possibilite a ele, ao sair da internação, ter garantida uma reinserção social real parece ser um grande problema.

Este problema pode ser refletido no resultado do relatório do Conselho Nacional de Justiça (CNJ) denominado Panorama Nacional: a execução das Medidas Socioeducativas de Internação (BRASIL, 2012a) demonstrando o alto índice de reincidência de infrações dos jovens, em torno de 54\%, e os crimes das reincidências são mais graves, ou seja, na internação de reincidência há maior ocorrência de atos infracionais resultantes da morte da vítima, o que demonstra que o objetivo de "ressocializar" e "reeducar" o jovem que conflitou a lei, conforme propõe o Estatuto da Criança e Adolescente (ECA) em seu art. 112, não está sendo efetivado neste sistema punitivo.

Assim, garantir a escolarização durante o período de internação para aqueles que, em sua maioria, já tinham se afastado da escola, pressupõe mudanças, não só em sentido formal, pois estas já existem nas legislações (C.F., ECA e o SINASE), mas sobretudo no sentido real, diríamos, material mesmo, isto é, ofertar a esses sujeitos atravessados pelas mazelas de sua condição de classe, outras possibilidades que despertasse o interesse pela escola.

\section{CONCLUINDO...}

Parte-se do entendimento, concordando com Araujo e Frigotto (2015, p. 162), que “[...] os fins da educação têm caráter social e político e que a finalidade da educação escolar deve ser a de promover o ser humano em suas amplas capacidades." Desse modo, compreende-se o processo de escolarização não como na mera instrução, certificação ou nem como uma mercadoria cujo valor aumenta de acordo com o aumento do número de anos de estudos, mas como formação humana que associe não só os conhecimentos produzidos pela humanidade, mas, juntamente com isso, formem sujeitos conscientes de sua situação 
histórica e social, capazes alterar as condições historicamente dadas, isto é, uma educação emancipadora.

Sob esse prisma, garantir a escolarização de pessoas que entraram em contato com o crime e foram sentenciados a cumprir uma pena (para os maiores de 18 anos) ou uma medida socioeducativa (para os de 12 até 18 anos) pode ser uma forma de fazê-los compreender as condicionalidades históricas de sua ação no mundo e de sujeitos de transformação, sem moralismo, vitimização ou criminalização, mas conscientes que fazem parte de uma sociedade de classes em que há forças dominantes associadas ao atual estágio do modo de produção capitalista, que não requerem, efetivamente, a universalização da escolarização básica de qualidade, mas que como instituição social, pode se articular às lutas e interesses das classes populares na construção de uma educação que emancipe, mesmo dentro do cárcere.

Diante deste contexto, é notória a necessidade de aprimoramento do sistema de justiça para que a sociedade e o Estado ofereçam não apenas uma resposta monolítica às situações geradoras de conflitos, mas disponha de outros sistemas, com outras respostas que pareçam mais adequadas diante da complexidade do fenômeno criminal, onde há a exclusão de direitos, que "[...] no contexto da mundialização do capital, assumem uma magnitude e uma gravidade sem precedentes." (FRIGOTTO, 2010, p. 422).

Poulantzas (1980), afirmou que o Estado tem um papel essencial nas “[...] relações de produção e na delimitação-reprodução das classes sociais, porque não se limita ao exercício da repressão física organizada. O Estado também tem um papel específico na organização das relações ideológicas e da ideologia dominante." E o direito tem importância fundamental na sociedade de classes, pois ele legitima as relações de produção na sociedade capitalista, tendo a ideologia como função "[...] organizar um consenso de certas classes e parcelas dominadas em relação ao poder público. A ideologia dominante consiste essencialmente num poder essencial da classe dominante" (POULANTZAS, 1980, p. 33). Nesse caso, o Poder Judiciário, sendo um dos aparelhos ideológicos e repressivo do Estado, tem por função elaborar e reproduzir esta ideologia e a divisão social do trabalho. Vale lembrar que a "[...] ideologia dominante intervém na organização dos aparelhos aos quais compete principalmente o exercício da violência física legítima (exército, polícia, justiçaprisão, administração)." (POULANTZAS, 1980, p. 34).

Estas 'engrenagens' colaboram para que as prisões (tanto para o jovem quanto para o adulto) sejam essenciais ao bom funcionamento do capitalismo. Visto que elas segregam fisicamente os internos e intimida visando disciplinar os que se mantêm fora dela, mas podem tornar-se uma ameaça à ordem constituída, convertendo-se em um paradigma de um novo modelo de gestão da miséria, que busca criminalizar comportamentos típicos das classes depauperadas. 
Nesse sentido, o Estado mais uma vez é obrigado a garantir o acesso à educação conforme determinam as legislações supracitadas, no entanto, se antes essa responsabilidade era partilhada com a família, agora é somente dele, visto que no período de cumprimento da pena (para os maiores de 18 anos) ou medida socioeducativa (para os menores de 18 anos), esses sujeitos ficam sob sua tutela.

O SINASE, assim como a CF e o ECA, responsabiliza o Estado, por meio da instalação e manutenção das Unidades de Atendimento Socioeducativas, a fornecer e manter a escolarização e profissionalização, tendo que assegurar um espaço destinado a salas de aulas apropriadas contando com sala de professores e local para funcionamento da secretaria e direção escolar e sala para a profissionalização no sistema de internação.

Eis o desafio que expressa garantir o direito a escolarização àqueles que, em sua maioria, já haviam se afastado da escola e que durante o cumprimento da medida socioeducativa são (re)inseridos no contexto escolar. A contradição está em incluir esses adolescentes e jovens quando estão aprisionados e, dependendo do seu bom desempenho, podem ter progressão ou encerramento de medida, cuja implicação é mais uma vez atropelar a trajetória educacional. Daí que o apoio do Estado aos egressos que proporcione uma real mudança nas condições materiais substituindo aquelas que o levaram para a criminalidade, torna-se fundamental.

\section{REFERÊNCIAS}

ARAUJO, R. M. de L.; RODRIGUES, D. do S. Referências sobre práticas formativas em educação profissional: o velho travestido de novo frente ao efetivamente novo. B. Téc. Senac: a R. Educ. Prof., Rio de Janeiro, v. 36, n.2, maio/ago. 2010.

ARAUJO, R. M. L.; FRIGOTTO, G. Práticas pedagógicas e ensino integrado. Revista Educação em Questão, v. 52, n. 38 maio/ago. 2015. Disponível em: < https://periodicos. ufrn.br/educacaoemquestao/issue/view/456>. Acesso em: 17 mar. 2017.

BRASIL. Conselho Nacional de Justiça. Relatório do Panorama Nacional - A execução das Medidas Socioeducativas de Internação Programa Justiça Jovem. Brasília, DF, 2012a.

BRASIL. Lei 8.069/1990. Estatuto da Criança e do adolescente. Brasília, 1990.

BRASIL. Lei 9.394/1996. Lei de Diretrizes e Bases da Educação. Brasília, 1996.

BRASIL. Lei $\mathrm{n}^{\mathrm{o}}$ 12.594/2012. Institui o Sistema Nacional de Atendimento Socioeducativo (SINASE), Brasília, DF, 2012b.

BRASIL. Ministério da Justiça. Departamento Penitenciário Federal. Levantamento Nacional de Informações Penitenciárias INFOPEN atualização Junho de 2016. Brasília, DF, 2017. 
BRASIL. Ministério da Justiça. Departamento Penitenciário Federal. Levantamento Nacional de Informações Penitenciárias INFOPEN. Junho de 2014. Brasília, DF, 2014.

CARRANO, P. C. R.; MARINHO, A. C.; OLIVEIRA, V. N. M. de. Trajetórias truncadas, trabalho e futuro: jovens fora de série na escola pública de ensino médio. Educ. Pesqui., v. 41, n. spe., p. 1439-1454, 2015. ISSN 1678-4634. Disponível em: <http://dx.doi.org/10. 1590/S1517-9702201508143413>. Acesso em: 10 mar. 2016.

CERQUEIRA, D.; LIMA, R.; BUENO, S.; VALENCIA, L.; HANASHIRO, O.; MACHADO, P., LIMA, A. Atlas da Violência 2017- IPEA, Brasília, Junho de 2017.

CONSELHO NACIONAL DO MINISTÉRIO PÚBLICO. Relatório da infância e juventude - Resolução no 67/2011: um olhar mais atento às unidades de internação e semiliberdade para adolescentes. Brasília, 2013.

ENGELS, F. A situação da classe trabalhadora na Inglaterra. São Paulo: Boitempo, 2010.

FRIGOTTO, G. Juventude, trabalho e educação no Brasil: perplexidades, desafios e perspectivas. In: NOVAES, R.; VANNUCHI, P. (Org.). Juventude e sociedade: trabalho, educação, cultura e participação. São Paulo, Fundação Perseu Abramo; Instituto Cidadania, 2004.

FRIGOTTO, G. Exclusão e/ou desigualdade social? Questões teóricas e político-práticas. Cadernos de Educação, Pelotas v. 37, p. 417- 442, set./dez. 2010. Disponível em: < file:///C:/Users/HP/Downloads/1593-2080-1-PB\%20(3).pdf>. Acesso em: 09 maio 2015.

FREITAS, R. C. F. Sistema punitivo e justiça restaurativa: os reflexos na escolarização e profissionalização na socioeducação. 2017. Tese (Doutorado) - Universidade Federal do Pará, Pará, 2017. Disponível em: <http://repositorio.ufpa.br/jspui/bitstream/2011/9336/1/ Tese_SistemaPunitivoJustica.pdf> Acesso em: 25 mar. 2018.

GIORGI, A. de. A miséria governada através do sistema penal. Trad. Sérgio Lamarão. Rio de Janeiro: Instituto Carioca de Criminologia; Revan, 2006.

GRAMSCI, A. Intelectuais e a organização da cultura. Rio de Janeiro: Civilização Brasileira, 1982.

JINKINGS, I. Sob o domínio do medo: controle social e criminalização da miséria no neoliberalismo. 2007. Tese (Doutorado) - Universidade Estadual de Campinas, Campinas, 2007. Disponível em: <http://repositorio.unicamp.br/jspui/handle/REPOSIP/280609>. Acesso em: 13 maio 2016.

JINKINGS, I. Cárcere e trabalho. In: ANTUNES, R. (Org.). Riqueza e miséria do trabalho no Brasil II. São Paulo: Boitempo, 2013. 
Artigo

doi: $10.20396 /$ rho.v18i2.8645881

LEMOS, F. C. S.; SCHEINVAR, E.; NASCIMENTO, M. L. do. Uma análise do acontecimento "crianças e jovens em risco". Psicol. Soc., v. 26, n. 1, p.158-164, 2014. ISSN 1807-0310. Disponível em: <http://dx.doi.org/10.1590/S0102-718220140001 00017>. Acesso em: 22 mar. 2018.

LOCKE, J. Segundo tratado sobre o governo civil. Tra. Magda Lopes e Marisa Lobo da Costa. Rio de Janeiro: Vozes, 2009. v. 8 n. 1.

MARX, K. O capital: crítica da economia política. Livro I, v. 2, 22. ed. Rio de Janeiro: Civilização Brasileira, 2008.

MELOSSI, D.; PAVARINI, M. Cárcere e fábrica. As origens do sistema penitenciário (século XVI-XIX). Rio de Janeiro: Revan, 2014.

MÉSZÁROS, I. Educação para além do capital. São Paulo. Boitempo, 2008.

MOURA, D. H. Educação básica e educação profissional e tecnológica: dualidade histórica e perspectivas de integração. Holos, ano 23, v. 2, 2007. Disponível em: <http://www2. ifrn.edu.br/ojs/index.php/HOLOS/article/viewFile/11/110>. Acesso em: 13 abr. 2016.

POULANTZAS, N. O estado, o poder, o socialismo. Rio de Janeiro: Graal, 1980.

RUSCHE, G.; KIRCHHEIMER, O. Punição e estrutura social. Rio de Janeiro: Revan, 2004.

SAVIANI, D. O Plano de desenvolvimento da educação: análise do projeto do Mec. Educ. Soc., Campinas, v. 28, n. 100 - Especial, p. 1231-1255, out. 2007. Disponível em: < http:// www.scielo.br/pdf/es/v28n100/a2728100.pdf>. Acesso em: 03 fev. 2016.

SAVIANI, D. O Lunar de Sepé: paixão, dilemas e perspectivas na educação. Campinas, SP: Autores Associados, 2014.

VOLPI, M. (Org.). Adolescentes privados de liberdade. A normativa nacional e internacional e reflexões acerca da responsabilidade penal. São Paulo: Cortez, 2014.

WACQUANT, L. As estratégias para cortar os custos do encarceramento em massa nos estados unidos. Novos Estudos. Cebrap, n. 64, p. 53-60, 2002.

WAISELFISZ, J. J. Mapa da violência 2013. Homicídios e juventude no Brasil. Brasília, 2013.

WAISELFISZ, J. J. Mapa da violência 2014. Os jovens do Brasil. Brasília, 2014. 


\section{Revista HIISTEMIDBR On-line}

Notas

${ }^{1}$ Universidade Federal do Pará -UFPA. rianecffreitas@ hotmail.com

${ }^{2}$ Universidade Federal do Pará-UFPA. gpsilva@ufpa.br

${ }^{3}$ Universidade Federal do Pará-UFPA. rlima@ufpa.br

${ }^{4}$ Universidade Federal do Pará -UFPA. anaraioldavi@gmail.com

${ }^{5}$ Universidade Federal do Pará -UFPA. cgs_costa1009@hotmail.com

${ }^{6}$ Art. $1^{\circ}$ O Sistema de Garantia dos Direitos da Criança e do Adolescente constitui-se na articulação e integração das instâncias governamentais e da sociedade civil, na aplicação de instrumentos normativos e no funcionamento dos mecanismos de promoção, defesa e controle para a efetivação dos direitos humanos da criança e do adolescente, nos níveis Federal, Estadual, Distrital e Municipal (CONSELHO NACIONAL DOS DIREITOS DA CRIANÇA E DO ADOLESCENTE, RESOLUÇÃO 113, DE 19 DE ABRIL DE 2006).

${ }^{7}$ A advertência consistirá em admoestação verbal, que será reduzida a termo e assinada.

${ }^{8} \mathrm{Em}$ se tratando de ato infracional com reflexos patrimoniais, a autoridade poderá determinar, se for o caso, que o adolescente restitua a coisa, promova o ressarcimento do dano, ou, por outra forma, compense o prejuízo da vítima.

${ }^{9}$ A prestação de serviços comunitários consiste na realização de tarefas gratuitas de interesse geral, por período não excedente a seis meses, junto a entidades assistenciais, hospitais, escolas e outros estabelecimentos congêneres, bem como em programas comunitários ou governamentais.

${ }^{10}$ A liberdade assistida será adotada sempre que se afigurar a medida mais adequada para o fim de acompanhar, auxiliar e orientar o adolescente.

${ }^{11} \mathrm{O}$ regime de semiliberdade pode ser determinado desde o início, ou como forma de transição para o meio aberto, possibilitada a realização de atividades externas, independentemente de autorização judicial.

${ }^{12}$ A internação constitui medida privativa da liberdade, sujeita aos princípios de brevidade, excepcionalidade e respeito à condição peculiar de pessoa em desenvolvimento.

${ }^{13}$ É um banco de dados que contém informações de todas as unidades prisionais brasileiras, incluindo dados de infraestrutura, seções internas, recursos humanos, capacidade, gestão, assistências, população prisional, perfil das pessoas presas, entre outros, que sintetiza informações sobre os estabelecimentos penais e a população prisional do Ministério da Justiça.

${ }^{14}$ Fonte: Levantamento Nacional de Informações Penitenciárias - Infopen, Junho/2016. Secretaria Nacional de Segurança Pública, Junho/2016; Fórum Brasileiro de Segurança Pública, dezembro/2015; IBGE, 2016.

${ }^{15}$ O InfoPen é um programa de computador (software) de coleta de dados do Sistema Penitenciário no Brasil.

${ }^{16}$ Fonte: Ministério da Justiça. A partir de 2005, dados do Infopen.

${ }^{17}$ Fonte: Levantamento Nacional de Informações Penitenciárias - Infopen, Junho/2016.

Submetido em: 30/04/2016

Aprovado em: 05/06/2018

Publicado em: 03/07/2018 